\title{
Article \\ Effect of Synthesis Method on Properties of Layered Double Hydroxides Containing Ni(III)
}

\author{
Olga V. Nestroinaia, Irina G. Ryltsova and Olga E. Lebedeva *D \\ Institute of Pharmacy, Chemistry and Biology, Belgorod State National Research University, \\ 308015 Belgorod, Russia; nestroynaya@bsu.edu.ru (O.V.N.); ryltsova@bsu.edu.ru (I.G.R.) \\ * Correspondence: olebedeva@bsu.edu.ru
}

\begin{abstract}
Unstable oxidation state +3 of nickel can be stabilized in the structure of layered double hydroxides, the resulting crystallinity and properties being dependent on the synthesis method. Three different wet chemical methods (co-precipitation at variable $\mathrm{pH}$, co-precipitation followed by hydrothermal treatment, co-precipitation with microwave treatment) were used to synthesize $\mathrm{Mg} / \mathrm{Ni}-\mathrm{Al}$ layered double hydroxides containing triply charged nickel cations. Lattice parameters of the samples synthesized by various methods were found to differ from each other by about $1.5 \%$. The most crystallized sample was obtained by hydrothermal synthesis. The oxidation state of nickel in the LDH samples was confirmed by XPS. TEM mapping gave evidence of the uniform distribution of nickel in all the samples. The LDHs' reduction with hydrogen and thermal transformations of the phase composition and morphology of LDHs were studied in detail. The properties of the samples synthesized by the different methods were shown to be quite similar.
\end{abstract}

Keywords: layered double hydroxides; nickel(III); co-precipitation; hydrothermal treatment; microwave treatment; XRD; XPS; TPR- $\mathrm{H}_{2}$

Citation: Nestroinaia, O.V.; Ryltsova,

I.G.; Lebedeva, O.E. Effect of

Synthesis Method on Properties of Layered Double Hydroxides Containing Ni(III). Crystals 2021, 11, 1429. https://doi.org/10.3390/ cryst11111429

Academic Editor: Aivaras Kareiva

Received: 23 October 2021

Accepted: 18 November 2021

Published: 21 November 2021

Publisher's Note: MDPI stays neutral with regard to jurisdictional claims in published maps and institutional affiliations.

\section{Introduction}

Layered double hydroxides (LDHs) or hydrotalcite-like compounds are layered basic salts. The general formula for this class of compounds is $\left[\mathrm{M}_{1-x}^{2+} \mathrm{M}_{x}^{3+}(\mathrm{OH})_{2}\right]^{x+}\left[\left(A^{n-}\right)_{x / n} \cdot m \mathrm{H}_{2} \mathrm{O}\right.$, where $\mathrm{M}^{2+}$ and $\mathrm{M}^{3+}$ are metal ions located in octahedral positions of brucite-like layers, and $\mathrm{A}^{\mathrm{n}-}$ stands for inorganic or organic anions that compensate the positive charge of brucite-like layers [1,2]. The structural features of hydrotalcite-like compounds give them a number of specific ion-exchange [3-5], sorption [6-8], electrical [9-11], catalytic [12-14], and magnetic properties [15-17].

The properties of LDHs are known to be significantly affected by cation-anion composition. Due to the easily reconstructed structure, it is possible to introduce cations of various metals into brucite-like layers, which makes it possible to regulate the properties of layered double hydroxides [18-21]. From the other point of view, LDHs are able to influence the properties of cations, changing them or, on the contrary, preserving them. The typical example is the stabilization of the unstable oxidation state of metals in a matrix of layered double hydroxides. Previously, our scientific group synthesized and characterized layered double hydroxides with unstable Ce(III) [22], Sn(II) [23], or Ni(III) [24] incorporated into brucite-like layers of LDHs.

Compounds containing trivalent nickel, however exotic they seem to be, are considered to be promising catalysts for the carbonation of polypropylene [25], the hydrocarboxylation of acetylene [26], the photocatalytic generation of hydrogen from water [27], and the electrocatalytic production of biodiesel [28].

The current study was aimed at the optimization of the synthesis method for obtaining nickel(III)-containing LDHs and the characterization of the effect of the synthesis method on the properties of the materials, in particular the degree of crystallinity, morphology, uniformity of element distribution, etc. 


\section{Materials and Methods}

\subsection{Materials and Preparation}

The synthesis of $\mathrm{Mg} / \mathrm{AlNi}$ layered double hydroxides was carried out by three different wet methods: co-precipitation at variable $\mathrm{pH}$, co-precipitation with hydrothermal treatment, co-precipitation with microwave treatment. The preset degree of substitution of nickel for aluminum was about 25 at.\%.

The following salts were used as sources of metal cations: $\mathrm{Mg}\left(\mathrm{NO}_{3}\right)_{2} \cdot 6 \mathrm{H}_{2} \mathrm{O}, \mathrm{Ni}\left(\mathrm{NO}_{3}\right)_{2} \cdot 6 \mathrm{H}_{2} \mathrm{O}$, $\mathrm{Al}\left(\mathrm{NO}_{3}\right)_{3} \cdot 9 \mathrm{H}_{2} \mathrm{O}$. All reagents were of analytical grade.

Aqueous solution of a mixture of $\mathrm{NaOH}$ and $\mathrm{Na}_{2} \mathrm{CO}_{3}$ with a molar ratio of reagents of 8:1 was used as a precipitant solution, and sodium hypochlorite $\mathrm{NaOCl}$ was applied as an oxidizer for nickel. The sodium hypochlorite solution was taken in a 1.5-fold molar excess with respect to the nickel content set during the synthesis.

Co-precipitation at variable $\mathrm{pH}$ was carried out by adding dropwise a precipitant solution to a solution containing the required amounts of salts. The total concentration of ions in the initial reaction mixture was $1 \mathrm{M}$, and the molar ratio of cations $\mathrm{M}^{2+}: \mathrm{M}^{3+}=3: 1$. During the synthesis, the $\mathrm{pH}$ of the mixture was kept approximately equal to 9-10. The precipitate was aged for $48 \mathrm{~h}$ under mother liquor. The sample obtained by this method is designated as $\mathrm{Mg} / \mathrm{AlNi} 25-\mathrm{c}$.

Hydrothermal synthesis of LDH was carried out in an Autoclave Engineers Parker autoclave at a temperature of $120^{\circ} \mathrm{C}$ and excessive pressure of about $1 \mathrm{~atm}$ for $8 \mathrm{~h}$. The volume of the autoclave was $50 \mathrm{~mL}$, and $90 \%$ of it was filled with the reagents. The process was performed under stirring at $350 \mathrm{rpm}$. The ratio of the components in the reaction mixture and the $\mathrm{pH}$ value were identical to those described above for the co-precipitation synthesis procedure. The sample obtained by this method is designated as Mg/AlNi25-ht.

Co-precipitation with microwave treatment was carried out in a MARS-6 reactor for $10 \mathrm{~min}$ at a power of $700 \mathrm{~W}$. The composition of the reaction mixture was similar to that used in the co-precipitation method. The sample obtained by this method is designated as $\mathrm{Mg} / \mathrm{AlNi} 25-\mathrm{mw}$.

In all cases, the precipitated products obtained by various methods were separated from the mother liquor, washed with distilled water, and dried at $120^{\circ} \mathrm{C}$.

To obtain the oxide forms, the samples were calcined at a temperature of $600{ }^{\circ} \mathrm{C}$ for $2 \mathrm{~h}$ (Mg/AlNi25-ox).

\subsection{Apparatus and Procedures}

\subsubsection{X-ray Diffraction (XRD)}

The phase composition was identified by powder X-ray diffraction (XRD). XRD was performed on a Rigaku Ultima IV diffractometer ( $\mathrm{CuK} \alpha$-radiation) (Rigaku Co., Tokyo, Japan) in measurement range $2 \theta 5-80^{\circ}$ with a scanning step of $0.02^{\circ}$, at a speed of $3^{\circ} / \mathrm{min}$. XRD patterns were registered using Bragg-Brentano reflection geometry. Before the measurements, the powders of LDHs were ground in agate mortar for $30 \mathrm{~min}$. Phase identification was performed using PXRD base PDF-2 (2014) with PDXL software (Rigaku Corporation). The cell parameters were calculated by Rietveld method using PDXL software (version 1.8.0.3, Rigaku Corporation) as well.

\subsubsection{Transmission Electron Microscopy (TEM)}

The morphology of the synthesized LDHs was studied by transmission electron microscopy on a JEM-2100 microscope (JEOL, Tokyo, Japan) at an operating voltage of $200 \mathrm{kV}$. Sample preparation was carried out by grinding the samples to a powder state with further dispersion in acetone under the action of ultrasound and deposition on a carbon film.

\subsubsection{Scanning Electron Microscopy (SEM) Combined with EDXA}

The elemental composition of the synthesized samples was determined using high-resolution scanning electron microscope QUANTA 200 3D FEI (FEI Company, 
Mahwah, NJ, USA), equipped with an energy dispersion analyzer of chemical composition at an operating voltage of $20 \mathrm{kV}$.

\subsubsection{X-ray Photoelectron Spectroscopy (XPS)}

The chemical state of atoms on the surface of synthesized layered double hydroxides was studied by X-ray photoelectron spectroscopy (XPS). The purpose of this analysis was to confirm oxidation of nickel(II) to nickel(III). The XPS measurements were carried out on a Thermo Fisher Scientific ESCALAB 220iXL spectrometer (VG Scientific, West Sussex, UK) with an energy range of $0-5000 \mathrm{eV}$ and a monochromatic $\mathrm{Al} \mathrm{K \alpha} \mathrm{X}$-ray source $(\mathrm{E}=1486.6 \mathrm{eV})$. The spot size on the sample was adjusted from 200 to $900 \mu \mathrm{m}$.

\subsubsection{Textural Characteristics}

Textural characteristics were studied by low-temperature nitrogen adsorption on a Microtrac BELSORP-mini (Microtrac Bel Co., Osaka, Japan) specific surface area and porosity analyzer II at a temperature of $77 \mathrm{~K}$. In order to remove physically sorbed water and carbon dioxide, the samples were heated at a temperature of $100-110^{\circ} \mathrm{C}$. The values of the specific surface area of the samples were calculated using BET equation.

\subsubsection{Temperature-Programmed Reduction $\left(\mathrm{TPR}-\mathrm{H}_{2}\right)$}

The reducibility of LDHs and the products of their thermal destruction were studied by temperature-programmed reduction (TPR).

Temperature-programmed reduction with hydrogen was carried out in an 8-channel stationary reactor system with a continuous flow, operating in parallel. Each quartz reactor (i.e., $6 \mathrm{~mm}$ ) was filled with $50 \mathrm{mg}$ of the corresponding sample with a particle size of 250-315 $\mu \mathrm{m}$, which had been pretreated at different temperatures: $\mathrm{LDH}$ at $200{ }^{\circ} \mathrm{C}$ and thermal degradation products at $500{ }^{\circ} \mathrm{C}$ in Ar flow $(80 \mathrm{~mL} / \mathrm{min})$ at a heating rate of $10{ }^{\circ} \mathrm{C} / \mathrm{min}$. The reduction was carried out in an $\mathrm{H}_{2} / \mathrm{Ar}$ flow (5:95) with a temperature interval of $10^{\circ} \mathrm{C} / \mathrm{min}$. Hydrogen consumption and water formation were monitored using OmniStar quadrupole mass spectrometer (Pfeiffer Vacuum, Asslar, Germany).

\subsubsection{Thermogravimetric and Differential Thermal Analysis}

Thermogravimetric and differential thermal analysis were performed on the NETZSCH STA 449 F3 Jupiter synchronous thermal analysis device (Netzsch, Selb, Germany). Measurements of changes in mass and thermal effects were carried out in the temperature range between $30^{\circ} \mathrm{C}$ and $950{ }^{\circ} \mathrm{C}$. The samples were heated in nitrogen atmosphere.

\section{Results}

The structure and phase composition of the synthesized samples were determined using X-ray diffraction. Powder XRD patterns of LDHs synthesized by various methods are shown in Figure 1. For all samples, the presence of five reflexes corresponding to basal reflections (003), (006), (009/012), (015), and (018) was recorded, and also the presence of two reflexes (110) and (113) forming a doublet at $2 \theta$ of $60^{\circ}$ was detected. Based on the results obtained, one can conclude that all three methods give rise to single-phase samples with a well-crystallized layered structure.

The most intense and narrow reflexes are observed in the X-ray patterns of the $\mathrm{Mg} / \mathrm{AlNi}$ 25-ht sample synthesized under hydrothermal conditions. This indicates that the sample has the highest degree of crystallinity. A well-split doublet at $2 \theta=60^{\circ}$ is also a confirmation of this fact.

For a sample obtained by co-precipitation followed by microwave treatment, the intensity of reflexes is significantly lower. 


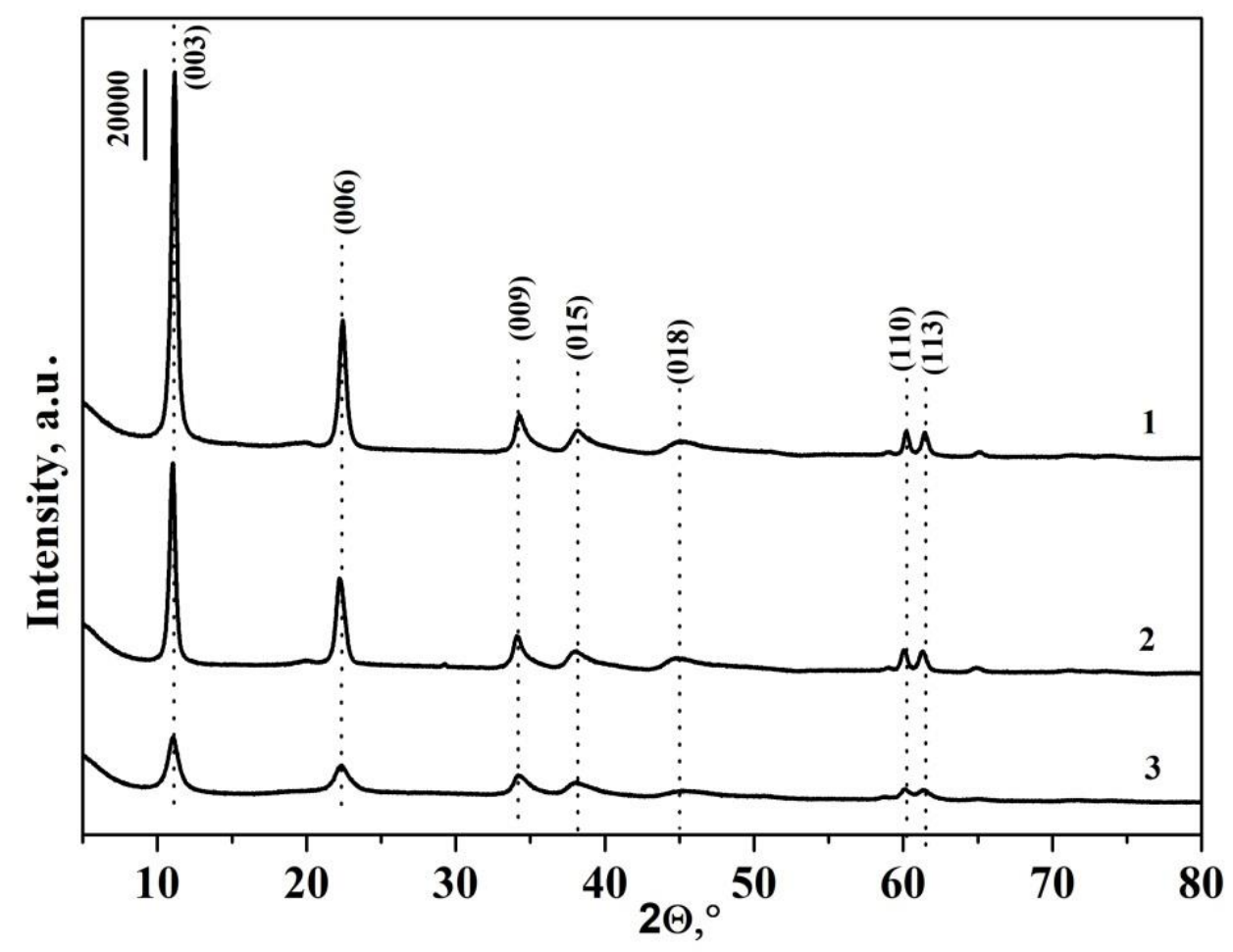

Figure 1. Powder XRD patterns: $1-\mathrm{Mg} / \mathrm{AlNi} 25-\mathrm{ht}$, 2-Mg/AlNi 25-c, 3-Mg/AlNi 25-mw.

The elemental composition of the obtained samples was determined using energy dispersion analysis. Figure 2 shows typical EDAX spectra of synthesized materials. Only those elements that were introduced during the synthesis were detected in the spectra. There are no signals of extra elements.

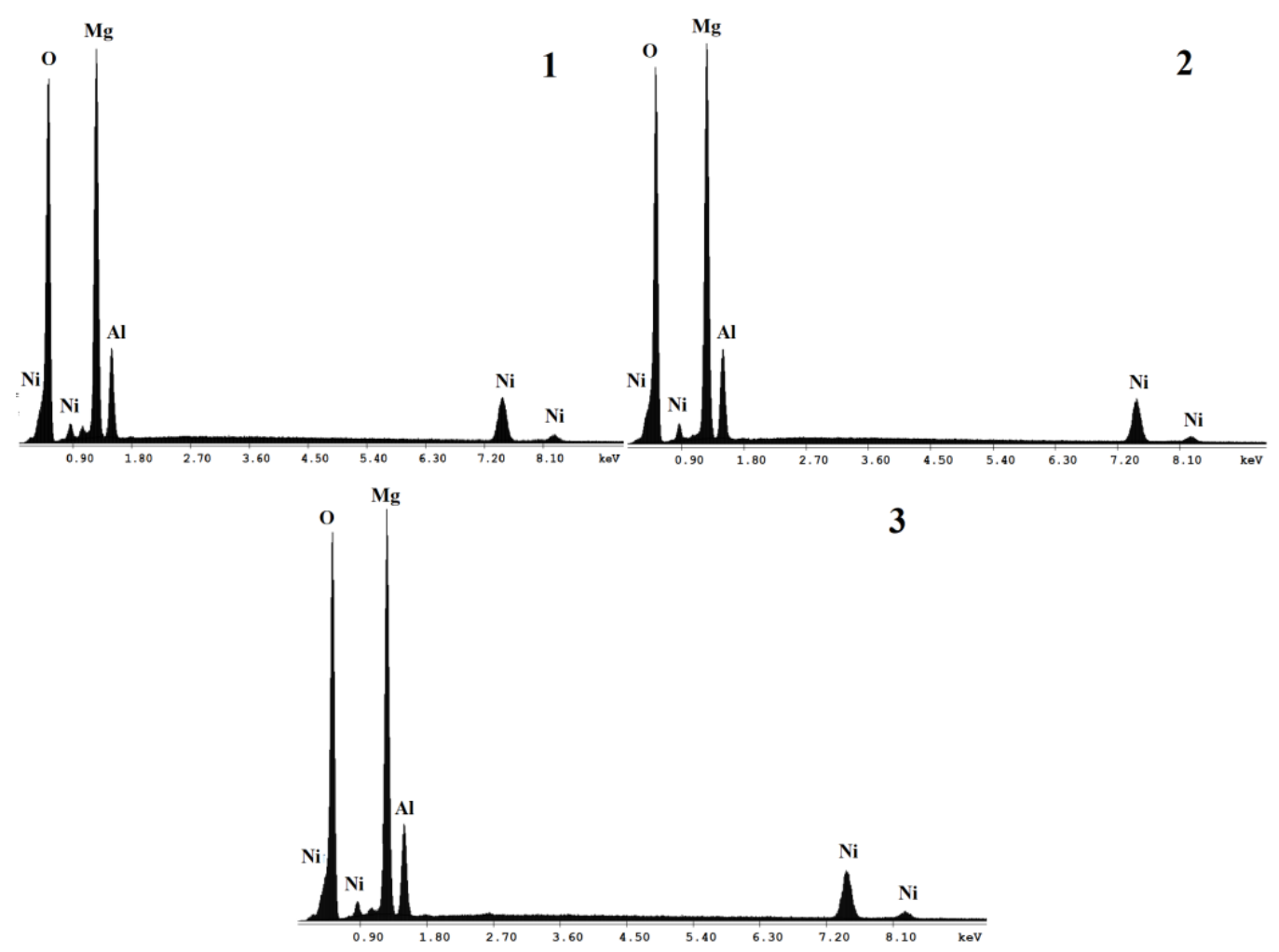

Figure 2. EDX spectra of samples: (1) Mg/AlNi 25-c, (2) Mg/AlNi 25-ht, (3) Mg/AlNi 25-mw. 
Table 1 shows the atomic fractions of metal cations calculated from EDAX. According to the data obtained, the molar ratio $\mathrm{M}^{2+} / \mathrm{M}^{3+}$ and the degree of substitution of aluminum cations for $\mathrm{Ni}(\mathrm{III})$ correspond to those set during the synthesis.

Table 1. Elemental composition, crystal lattice parameters and textural characteristics of LDHs synthesized by different methods.

\begin{tabular}{|c|c|c|c|c|c|c|c|}
\hline \multirow{2}{*}{ Sample } & \multicolumn{3}{|c|}{ Metal Ion Content, Atomic Fraction } & \multirow{2}{*}{$\mathrm{M}^{2+} / \mathrm{M}^{3+}$} & \multirow{2}{*}{$c, \AA$} & \multirow{2}{*}{$a, \AA$} & \multirow{2}{*}{$\mathrm{S}, \mathrm{m}^{2} / \mathrm{g}$} \\
\hline & $\mathrm{Mg}^{2+}$ & $\mathrm{Al}^{3+}$ & $\mathrm{Ni}^{3+}$ & & & & \\
\hline $\mathrm{Mg} / \mathrm{Al} \mathrm{Ni} 25-\mathrm{c}$ & 1.224 & 0.325 & 0.124 & 2.72 & $24.01 \pm 0.05$ & $3.06 \pm 0.01$ & 61 \\
\hline Mg/Al Ni 25-ht & 1.235 & 0.333 & 0.121 & 2.72 & $23.77 \pm 0.05$ & $3.08 \pm 0.01$ & 72 \\
\hline $\mathrm{Mg} / \mathrm{Al} \mathrm{Ni} 25-\mathrm{mw}$ & 1.201 & 0.329 & 0.134 & 2.61 & $24.06 \pm 0.05$ & $3.06 \pm 0.01$ & 70 \\
\hline
\end{tabular}

For all the samples, mapping analysis was conducted to confirm the uniformity of element distribution (Figure 3). From the data presented, it can be seen that atoms of all metals are present in the sample and are evenly distributed throughout its volume. For samples obtained by different methods, the pictures are similar.
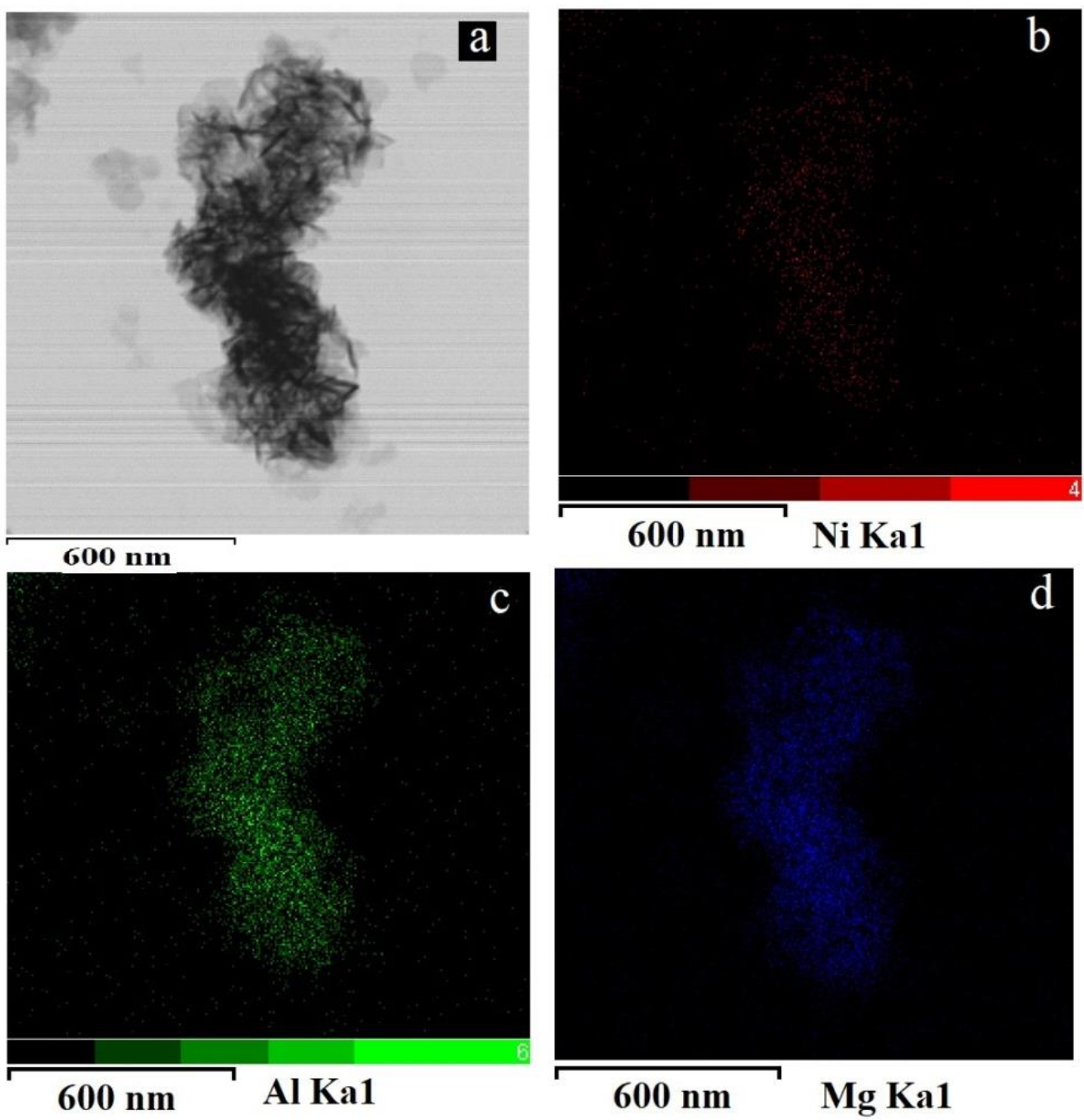

Figure 3. TEM mapping of $\mathrm{Mg}, \mathrm{Al}$ and $\mathrm{Ni}$ for $\mathrm{Mg}$ / AlNi 25-ht sample: (a) TEM image, (b) nickel space distribution, (c) aluminum distribution, (d) magnesium distribution. 
The experimental XRD in R-3m symmetry cell parameters is also presented in Table 1. The parameters $c$ and a of the crystal lattice correlate with the size of the interlayer space and the distance between neighboring cations in the brucite-like layer, respectively. The difference in the parameters for various samples is not more than $1.5 \%$.

The specific surface area of the layered double hydroxides is also included in Table 1. The values are comparable for the three samples.

The morphology of the obtained samples was studied by transmission electron microscopy (TEM) (Figure 4). For the Mg/AlNi25-c and Mg/AlNi25-ht samples, wellcrystallized aggregates of lamellar hexagonal particles dominate. For the Mg/AlNi25-mw sample, crystals of a different shape are observed along with hexagonal particles.

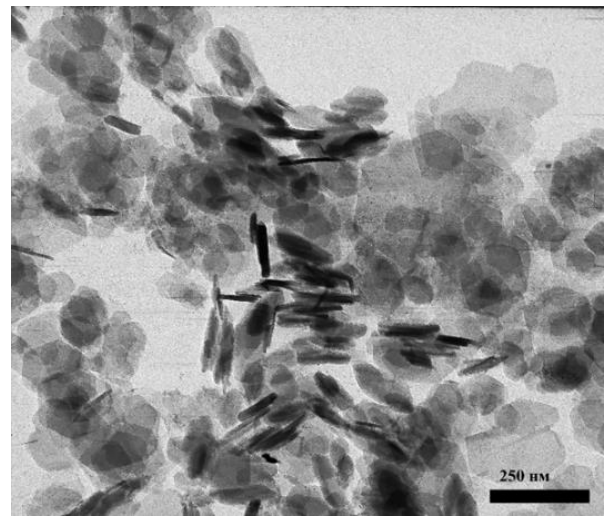

(a)

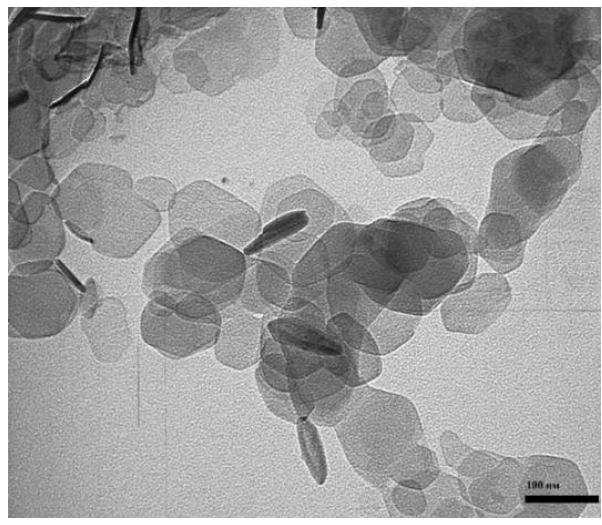

(b)

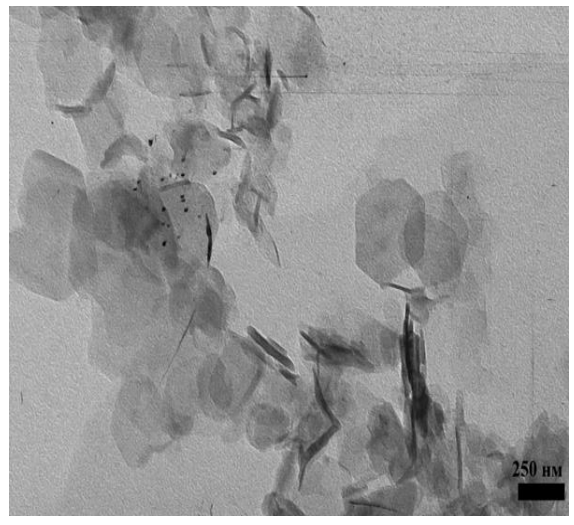

(c)

Figure 4. TEM micrographs of: (a) Mg/AlNi 25-c, (b) Mg/AlNi 25-ht, (c) Mg/AlNi 25-mw.

The thermal stability of the samples was studied by TG-DSC analysis. Figure 5 shows the TG-DTA curves for the Mg/AlNi25-c sample. There are two main stages of mass loss on the thermogravimetric curve. Two endothermic effects were recorded on the DTA curves, which were consistent with the TG data.

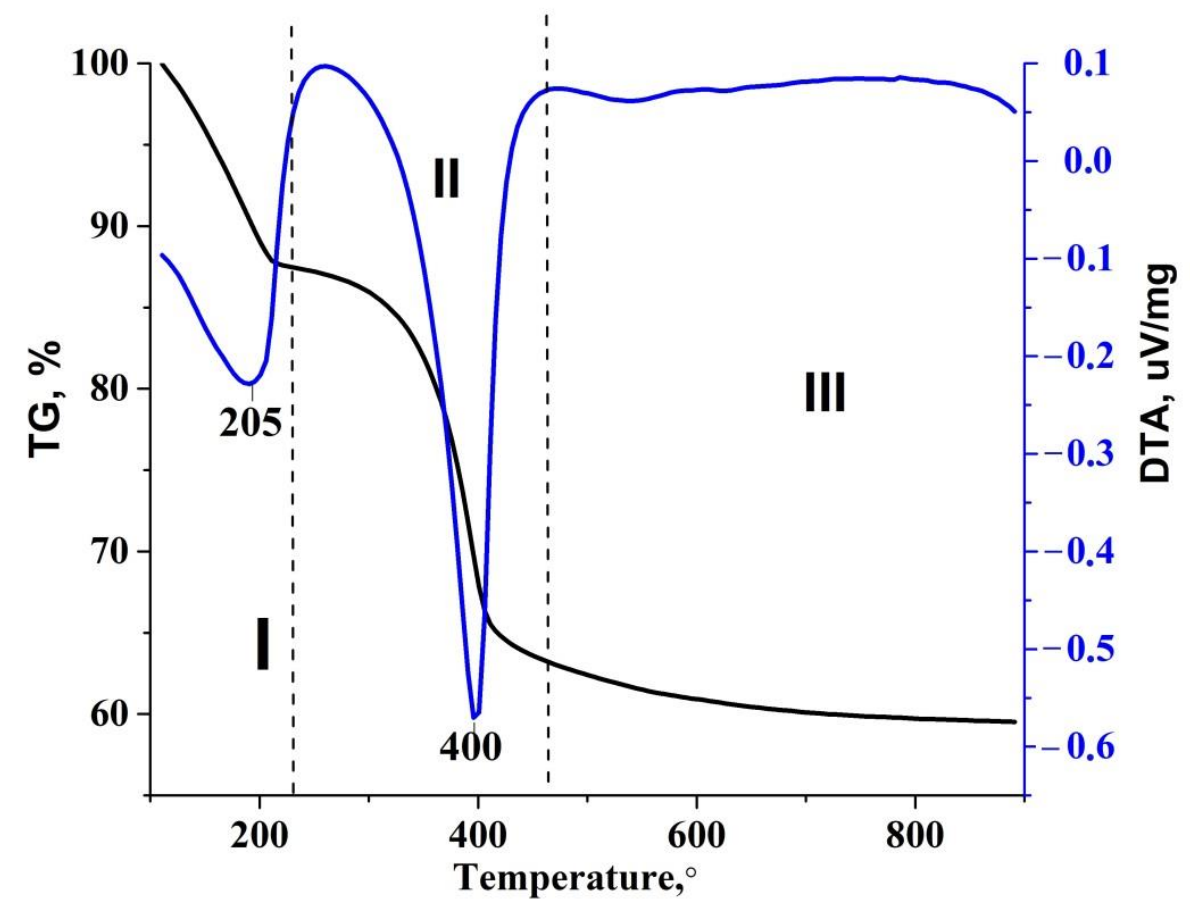

Figure 5. TG-DTA curves of $\mathrm{Mg} / \mathrm{AlNi}-25-\mathrm{c}$. 
Typically for LDHs, the first stage of mass loss is caused by the loss of both sorbed $\left(20-130^{\circ} \mathrm{C}\right)$ and crystallized interlayer $\left(130-240{ }^{\circ} \mathrm{C}\right)$ water [29]. However, the additional effect for $\mathrm{Ni}(\mathrm{III})$ is hidden in this range. Nickel(III) is known to transform easily into a more stable divalent state at a temperature exceeding $138^{\circ} \mathrm{C}$ [30]. This process is accompanied by the release of molecular oxygen and a change in color from black to green. It can be assumed that in the range of $130-240^{\circ} \mathrm{C}$, a loss of mass partially results from the release of oxygen during the reduction of $\mathrm{Ni}(\mathrm{III})$ to $\mathrm{Ni}(\mathrm{II})$.

The second stage of mass loss is associated with the dehydroxylation of brucite-like layers and the removal of carbonates from the interlayer space.

For all samples synthesized by different methods, the TG-DTA curves have the same appearance. However, for sample Mg/AlNi-25-mw, a 5-6-degree shift of the minima of endothermic effects towards lower temperatures was recorded.

For the sample $\mathrm{Mg} / \mathrm{AlNi}-25-\mathrm{c}$, the thermal behavior and phase transitions were studied in detail. Figure 6 presents the XRD patterns of the sample calcined at different temperatures. It can be seen that up to the temperature of $300^{\circ} \mathrm{C}$, the structure of hydrotalcite is preserved though a decrease in the intensity of recorded peak starts, which is likely to originate from the water removal from the interlayer space. At $350{ }^{\circ} \mathrm{C}$, diffractograms contain only two reflections belonging to the class of hydrotalcites.

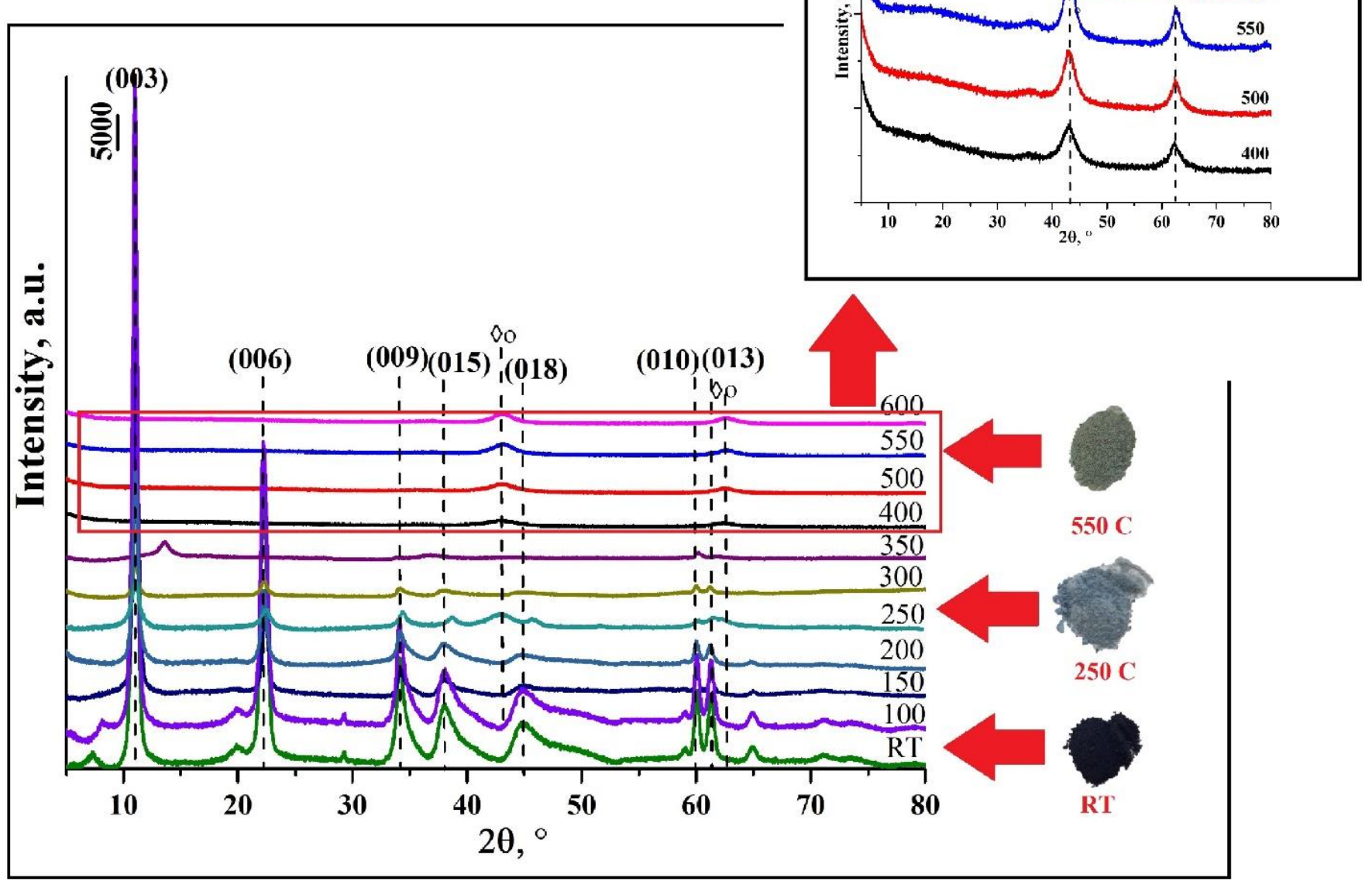

Figure 6. Powder XRD patterns of $\mathrm{Mg} / \mathrm{AlNi}-25-\mathrm{c}$ calcined at different temperatures. 
An increase in temperature above 400 degrees leads to the complete destruction of the $\mathrm{LDH}$ structure and the formation of a mixture of oxides, which at a temperature of 500-600 ${ }^{\circ} \mathrm{C}$ are converted into spinel phases.

Figure 6 also shows the change in the color of the LDH depending on the heating temperature. At room temperature, the sample is black; further heating to $250{ }^{\circ} \mathrm{C}$ leads to a change in the color of the sample to gray-blue, which is most likely associated with the onset of the reduction of nickel. Further heating leads to the complete transformation of $\mathrm{Ni}(\mathrm{III})$ into $\mathrm{Ni}(\mathrm{II})$.

The thermal transformations for two other LDH samples were demonstrated to be essentially the same.

The change in the morphology of LDHs upon heating was studied using transmission electron microscopy. In Figure 7, it is clearly seen that with heating the hexagonal flakes gradually cease to be distinguishable. After calcination at $200^{\circ} \mathrm{C}$, they are still clearly visible in micrographs, and it is almost impossible to distinguish them after calcination at $400{ }^{\circ} \mathrm{C}$. Oxides are formed at $400{ }^{\circ} \mathrm{C}$, and at $600{ }^{\circ} \mathrm{C}$ oxides are agglomerated into spinel phases.
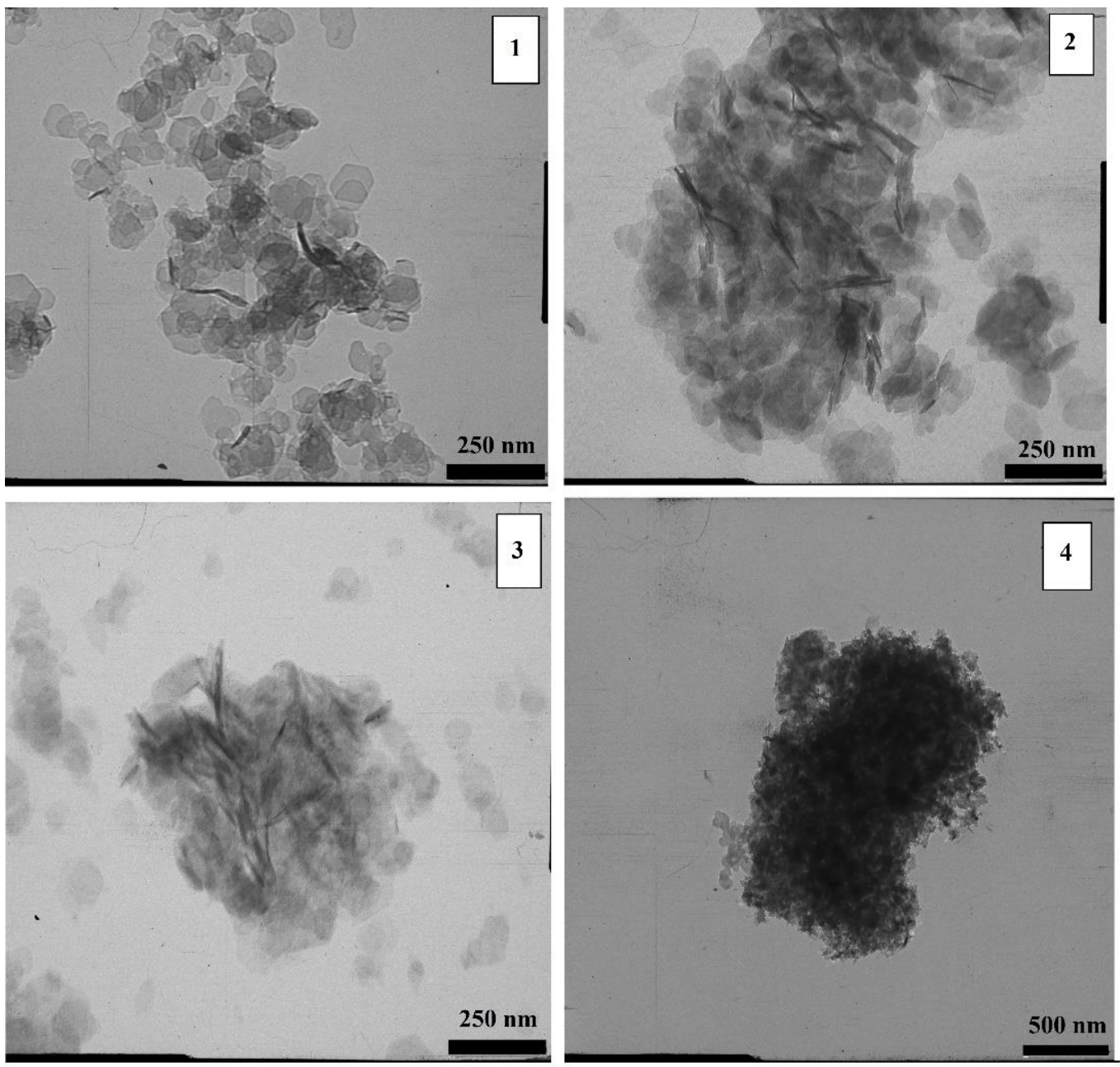

Figure 7. TEM micrographs of Mg/AlNi 25-ht heated at different temperatures: (1) RT, (2) $200{ }^{\circ} \mathrm{C}$, (3) $400{ }^{\circ} \mathrm{C}$, (4) $600{ }^{\circ} \mathrm{C}$.

The specific surface area of the $\mathrm{Mg} / \mathrm{AlNi} 25-\mathrm{c}$ sample calcined at $600{ }^{\circ} \mathrm{C}$ is $150 \mathrm{~m}^{2} / \mathrm{g}$.

In the current research, the determination of the oxidation state of nickel in the LDH samples was the most challenging. XPS permitted us to obtain information about the nickel oxidation state. Binding energies for $\mathrm{Ni}$ (III) and $\mathrm{Ni}$ (II) have close values, and this fact causes difficulties in the identification of nickel species. In the publication of Haoyan Liang et al., 
it was shown that the peak at $854.7 \mathrm{eV}$ corresponds to $\mathrm{Ni}(\mathrm{III})$, and the peak at $856.1 \mathrm{eV}$ corresponds to $\mathrm{Ni}(\mathrm{II})$ [31]. These values were taken as references. The binding energy for nickel from $\mathrm{NiO}$ obtained by calcining LDHs acted for a comparison.

Figure 8a shows overview X-ray photoelectron spectra of the samples of $\mathrm{Mg} / \mathrm{AlNi}-25$ synthesized under different conditions, as well as the spectrum of the sample Mg/AlNi-25ox after calcination at $600{ }^{\circ} \mathrm{C}$. The survey XPS spectra for all LDH samples have an identical form, and the signals of all elements have comparable intensities with the exception of the signal corresponding to the energy $\mathrm{O} 1 \mathrm{~s}$.

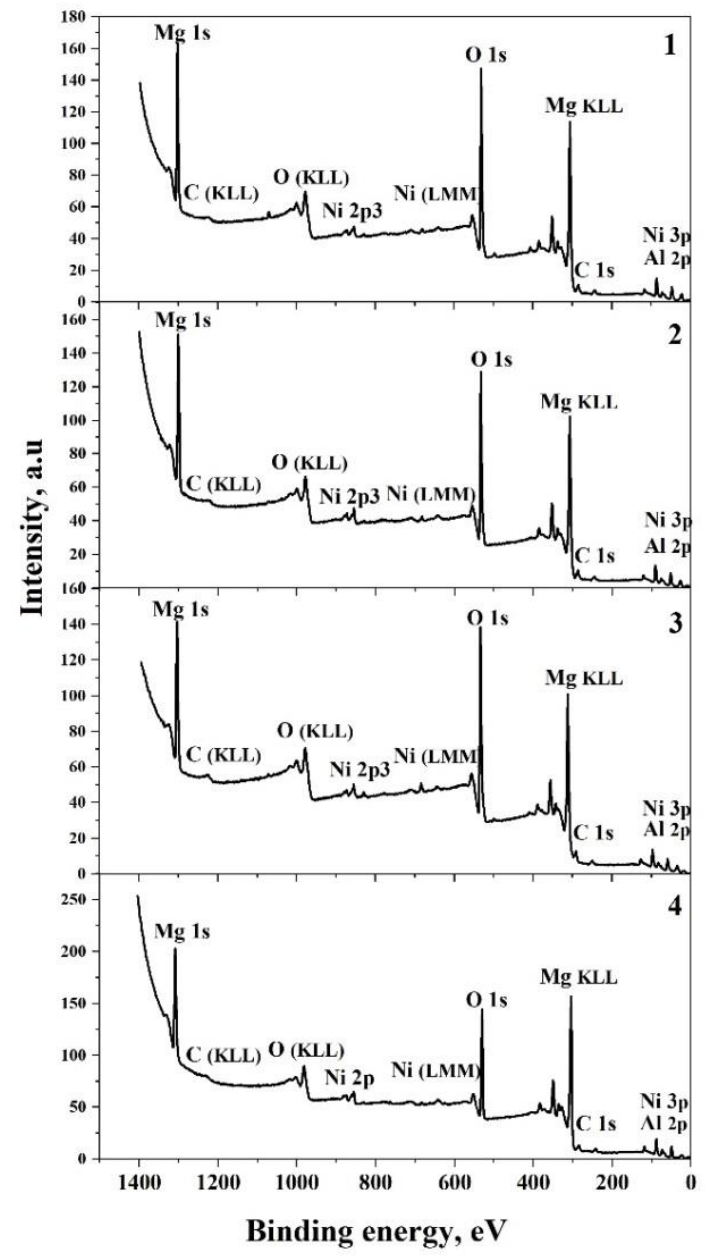

(a)

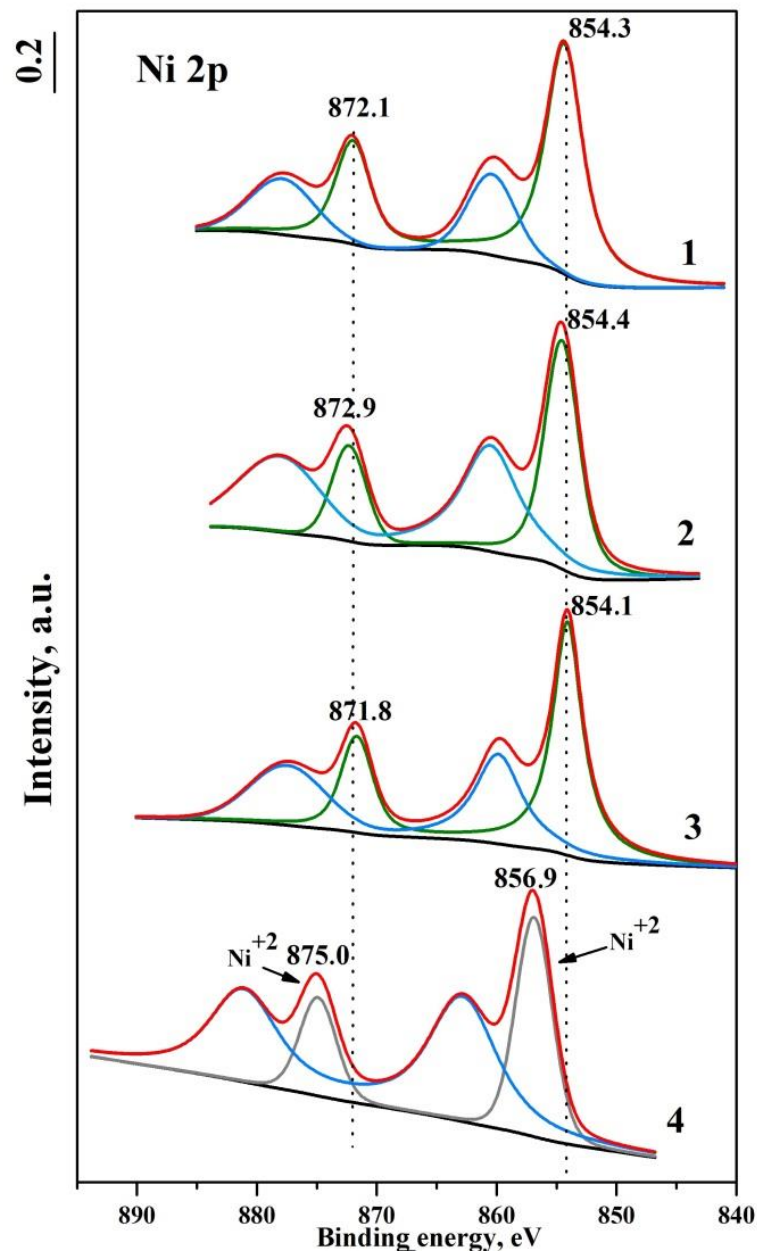

(b)

Figure 8. (a) XPS survey spectra and (b) spectra of the levels of $\mathrm{Ni} 2 \mathrm{p}$ atoms of the $\mathrm{Mg} / \mathrm{AlNi}-25$ sample, synthesized under different conditions: $1-\mathrm{Mg}$ / AlNi-25-c, 2-Mg/AlNi-25-ht, 3-Mg/AlNi-25-mw, 4-Mg/AlNi25-ox.

Figure $8 \mathrm{~b}$ shows the XPS spectra of the Ni2p in LDH samples and mixed oxides. The presence of two main lines (Ni2p1/2 and Ni2p3/2) and two satellites was recorded for all samples. The difference between binding energies of nickel in LDHs and in the calcined sample gives evidence of the different oxidation states of nickel in the LDHs and in calcined samples. $\mathrm{Ni}(\mathrm{III})$ is definitely present in all the LDH samples.

Unfortunately, the content of nickel(III) in the materials could not be determined quantitatively because of the presence of aluminum cations and the overlapping $\mathrm{Al}$ and $\mathrm{Ni}$ lines in XPS spectra.

Oxidative properties of $\mathrm{Ni}(\mathrm{III})$ in $\mathrm{LDH}$ were studied by hydrogen TPR. Figure 9 a shows the TPR profiles of $\mathrm{Mg} / \mathrm{AlNi}-25-\mathrm{c}, 2-\mathrm{Mg} / \mathrm{AlNi25}-\mathrm{ox}$. The TPR profile of $\mathrm{LDH}$ contains 
weak signals of hydrogen absorption at low temperatures in the range of $100-400{ }^{\circ} \mathrm{C}$, a signal at $400-550{ }^{\circ} \mathrm{C}$ and the beginning of a very broad signal in the high-temperature region (above $750{ }^{\circ} \mathrm{C}$ ).

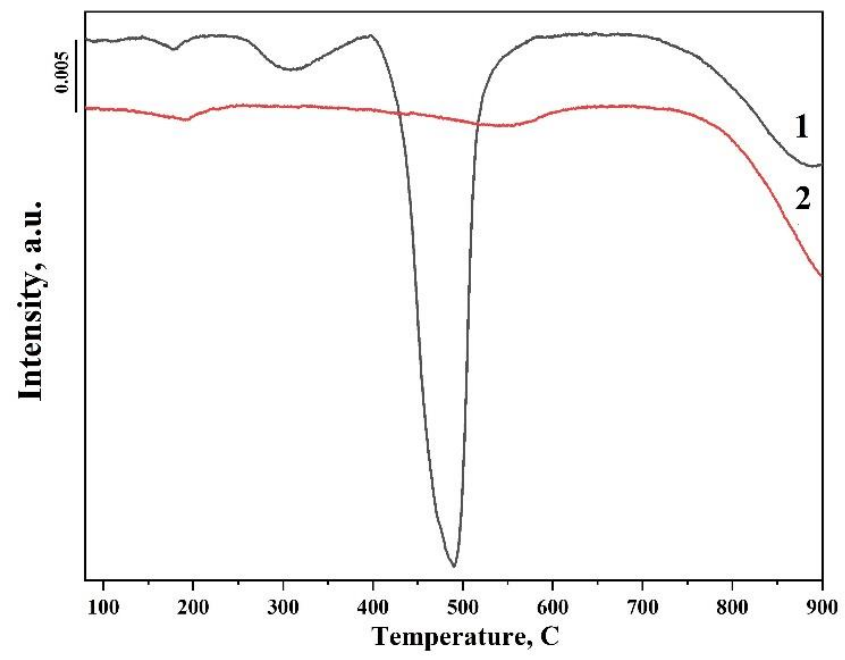

(a)

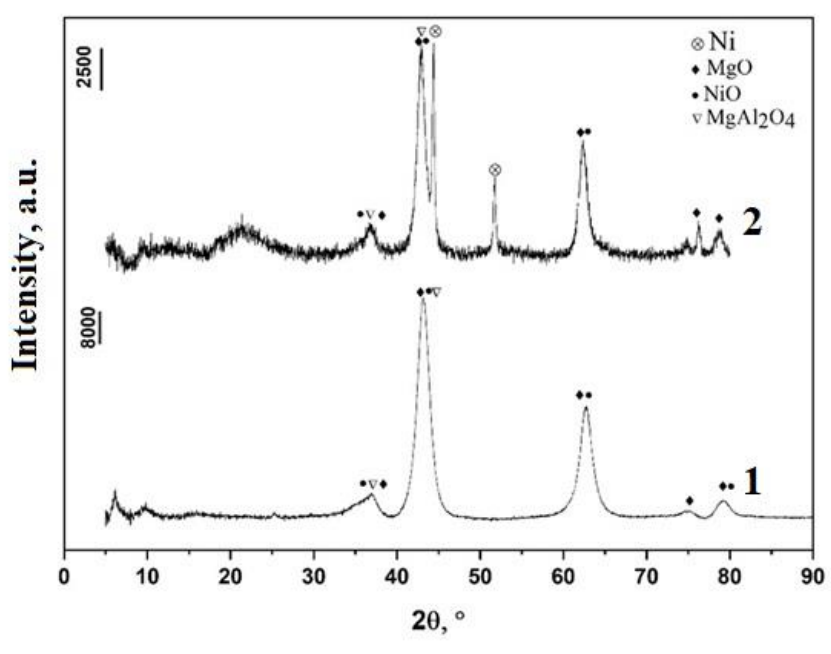

(b)

Figure 9. (a) $\mathrm{H}_{2}$-TPR profiles of $1-\mathrm{Mg} / \mathrm{AlNi}-25-\mathrm{c}, 2-\mathrm{Mg} / \mathrm{AlNi} 25-\mathrm{ox}$; (b) X-ray diffraction patterns for $\mathrm{Mg} / \mathrm{AlNi}-25-\mathrm{c}$ : 1 -original, 2-reduced.

It was already mentioned that nickel(III) oxide, when heated above $138^{\circ} \mathrm{C}$, is reduced to $\mathrm{NiO}$. However, nickel(III) in layered double hydroxides seems to be stabilized. The lowtemperature signals are so weak that they can be attributed to the reduction of nickel ions located on the surface. The peak located in the temperature range of $400-550{ }^{\circ} \mathrm{C}$ is likely to refer directly to the reduction of the majority of $\mathrm{Ni}$ (III) located inside brucite-like layers.

The appearance of a signal in the region of high temperatures is probably due to the reduction of $\mathrm{Ni}(\mathrm{II})$ to $\mathrm{Ni}^{0}$.

Figure $9 \mathrm{~b}$ shows $\mathrm{X}$-ray diffraction patterns for the $\mathrm{Mg} / \mathrm{AlNi}-25-\mathrm{c}$ sample after thermal destruction and temperature-programmed reduction. According to the XRD results for the $\mathrm{Mg} / \mathrm{AlNi}-25$ sample after TPR- $\mathrm{H}_{2}$, the presence of peaks corresponding to both nickel oxide $\mathrm{NiO}$ and metallic nickel $\mathrm{Ni}^{0}$ is observed, which signifies the incomplete reduction of nickel.

\section{Discussion}

Nickel(III) is known to be quite unstable. Only a few publications concerning compounds of trivalent nickel appear each decade. The successful synthesis of the single-phase hydrotalcite-like layered double hydroxide with $\mathrm{Ni}$ (III) via co-precipitation and the primary characteristics of this material were described in our previous publication [24]. However, it was not obvious that nickel could be incorporated in brucite-like layers of LDHs under conditions other than slow co-precipitation with subsequent long-term ageing. The efficiency of an application of a short-term microwave procedure was especially doubtful. Nevertheless, the XRD data described above demonstrate the formation of the LDH structure as a result of three different synthesis methods-co-precipitation, hydrothermal synthesis and microwave-assistant synthesis. Hence, one can conclude that the location of Ni(III) in the brucite-like layers stabilizes this non-typical oxidation state of nickel regardless of the route of synthesis. This may be owing to either steric protection inside the layer or the higher stability of the state of the ion located in the layer.

Nickel(III) stabilization in the structure of the brucite-like layer of the LDH is unambiguously confirmed by X-ray photoelectron spectroscopy (XPS). According to the XPS 
data presented above, nickel cations are in a trivalent state in all LDH samples synthesized by different methods.

The main difference between the three samples was observed in their crystallinity. Obviously, the sample synthesized by the microwave-assistant method has lower and broader reflexes in the XRD pattern (Figure 1) and more obscure morphology of particles in TEM images (Figure 4). In addition, TG-DSC results correlate with the other data since the sample in question starts thermal transformation at slightly lower temperatures than others. This might be caused by the relatively disordered lattice of the sample. However, no extraneous phases were detected in this sample. Moreover, the results of TEM mapping (Figure 3) confirm the uniform distribution of nickel in the samples. It is worth noting that the microwave-assistant method of LDH preparation has significant advantages due to its short time and relatively low energy consumption, which in some cases may play a more important role than the high crystallinity of LDHs.

The parameters of the crystal lattice for the three samples have a slight distinction, while the chemical composition is essentially the same (Table 1). It is necessary to take into account that the parameters of the LDH lattice may depend on the amount of water in the interlayer space and on the order of the brucite-like layer. Most likely, the lowest $c$ value for the sample synthesized under hydrothermal conditions is due to its highest crystallinity. The obtained results on parameter values, in general, indicate a successful isomorphic substitution of aluminum in the hydrotalcite structure for $\mathrm{Ni}(\mathrm{III})$ ions with a larger radius compared to $\mathrm{Al}(\mathrm{III})$. The evidence of the incorporation of nickel into the hydrotalcite structure is an increase in the parameter $c$, which for all synthesized samples exceeds the value of $22.9 \AA$ Á typical for aluminum magnesium hydrotalcite.

The synthesis of layered double hydroxides is known to result in materials replete with stacking faults $[32,33]$. This kind of disorder is due to $\mathrm{LDH}$ polytypism and the stacking faults are an intergrowth of $3 \mathrm{R}_{1}$ and $2 \mathrm{H}_{1}$ polytypes [32]. The fault formation can be detected by the analysis of XRD patterns. In particular, a comparison of the diffractograms of our samples with the examples given in $[32,33]$ permits us to suppose that the XRD patterns correspond to the $3 \mathrm{R}_{1}$ polytype with $2 \mathrm{H}_{1}$ stacking faults. It is noteworthy that all three samples synthesized by different methods demonstrate quite similar XRD patterns with comparable shape and asymmetry of peaks. Apparently, this leads to the conclusion that the synthesis method used does not greatly affect the order-disorder in the LDHs.

Thermal transformations of LDHs containing Ni(III) are quite usual for this class of compounds. The only unexpected fact was the hindered reducibility of the samples by hydrogen. This fact could be considered as an additional example of $\mathrm{Ni}$ (III) stabilization in the LDH lattice. Perhaps it is an argument in favor of the assumption concerning hindered access of the reagents towards the Ni(III) located in the structure of the metal hydroxide layer.

Thus, the efficient methods of LDH synthesis are not restricted to classical co-precipitation. The application of different approaches was demonstrated not to significantly affect the structure and properties of LDHs.

Author Contributions: Conceptualization, O.E.L. and I.G.R.; methodology, O.E.L.; investigation, O.V.N. and I.G.R.; writing—original draft preparation, O.V.N.; writing—review and editing, O.E.L.; visualization, O.V.N.; supervision, O.E.L. All authors have read and agreed to the published version of the manuscript.

Funding: This research received no external funding.

Acknowledgments: The authors thank the staff and administration of the Center of Common Use of Equipment of NRU "BelSU" for the technical support of the research.

Conflicts of Interest: The authors declare no conflict of interest. 


\section{References}

1. Cavani, F.; Trifiro, F.; Vaccari, A. Hydrotalcite-type anionic clays: Preparation, properties and applications. Catal. Today 1991, 11, 173-301. [CrossRef]

2. Forano, C.; Hibino, T.; Leroux, F.; Taviot-Gueho, C. Handbook of Clay Science; Bergaya, F., Theng, B.K.G., Lagaly, G., Eds.; Elsevier: Amsterdam, The Netherlands, 2006; Volume 1, pp. 1021-1095.

3. Haraketi, M.; Hosni, K.; Srasra, E. Intercalation behavior of salicylic acid into calcined Cu-Al-layered double hydroxides for a controlled release formulation. Surf. Eng. Appl. Electrochem. 2017, 53, 360-370. [CrossRef]

4. Dwiasi, D.W.; Mudasir, M.; Roto, R. Ion Exchange of Benzoate in Ni-Al-Benzoate Layered Double Hydroxide by Amoxicillin. Open Chem. 2019, 17, 1043-1049. [CrossRef]

5. Rives, V.; Arco, M.; Martín, C. Intercalation of drugs in layered double hydroxides and their controlled release: A review. Appl. Clay Sci. 2014, 88-89, 239-269. [CrossRef]

6. Lei, C.; Zhu, X.; Zhu, B.; Jiang, C.; Le, Y.; Yu, J. Superb adsorption capacity of hierarchical calcined Ni/Mg/Al layered double hydroxides for Congo red and Cr(VI) ions. J. Hazard. Mater. 2017, 321, 801-811. [CrossRef] [PubMed]

7. Zhang, D.; Liu, X.Y.; Zhao, H.T.; Yang, L.; Lü, T.; Jin, M.Q. Application of hydrotalcite in soil immobilization of iodate (IO $\left.{ }^{3-}\right)$. RSC Adv. 2018, 38, 21084-21091. [CrossRef]

8. Johnston, A.L.; Lester, E.; Williams, O.; Gomesa, R.L. Understanding Layered Double Hydroxide properties as sorbent materials for removing organic pollutants from environmental water. J. Environ. Chem. Eng. 2021, 9, 105197. [CrossRef]

9. Dipali, S.; Sachin, A.P.; Seong, H.; Jae, C. CoFe layered double hydroxide for enhanced electrochemical performance. J. Electroanal Chem. 2020, 862, 11-40.

10. Wang, W.; Zhang, N.; Shi, Z.; Ye, Z.; Gao, Q.; Zhi, M.; Hong, Z. Preparation of Ni-Al layered double hydroxide hollow microspheres for supercapacitor electrode. Chem. Eng. J. 2018, 338, 55-61. [CrossRef]

11. Iguchi Sh Kikkawa, S.; Teramura, K.; Hosokawa, S.; Tanaka, T. Investigation of the electrochemical and photoelectrochemical properties of Ni-Al LDH photocatalysts. Phys. Chem. Chem. Phys. 2016, 18, 13811-13819. [CrossRef]

12. Meng, Y.; Luo, W.; Xia Sh Ni, Z.H. Preparation of Salen-Metal Complexes (Metal = Co or Ni) Intercalated ZnCr-LDHs and Their Photocatalytic Degradation of Rhodamine B. Catalysts 2017, 7, 143. [CrossRef]

13. Mantovani, K.M.; Westrup KC, M.; da Silva Junior, R.M.; Jaerger, S.; Wypych, F.; Nakagaki, S. Oxidation catalyst obtained by the immobilization of layered double hydroxide/Mn(iii) porphyrin on monodispersed silica spheres. Dalton Trans. 2018, 47, 3068-3073. [CrossRef]

14. Mac Leod, T.; Kopylovich, M.M.; Guedes da Silva, F.; Mahmudov, K.; Pombeiro, A. Copper(II) complexes of arylhydrazones of $\beta$-diketones immobilized on $\mathrm{Zn}$-Al layered double hydroxides as effective recyclable catalysts for peroxidative oxidation of alkanes. Appl. Catal. A 2012, 439, 15-23. [CrossRef]

15. Nestroinaia, O.V.; Ryl'tsova, I.G.; Yapryntsev, M.N.; Lebedeva, O.E. Effect of the synthesis method on the phase composition and magnetism of layered double hydroxides. Inorg. Mater. 2020, 7, 747-753. [CrossRef]

16. Abellen, G.; Carrasco, J.; Coronado, E. Room temperature magnetism in layered double hydroxides due to magnetic nanoparticles. Inorg. Chem. 2013, 52, 7828-7830. [CrossRef] [PubMed]

17. Li, Q.; Xing, L.; Lu, X.; Li, N.; Mingxiang, X. Magnetic properties of Mg/Co(II)-Al/Fe(III) layered double hydroxides. Inorg. Chem. Commun. 2015, 52, 46-49. [CrossRef]

18. Chowdhury, P.R.; Bhattacharyya, K.G. Ni/Ti layered double hydroxide: Synthesis, characterization and application as a photocatalyst for visible light degradation of aqueous methylene blue. Dalton. Trans. 2015, 44, 6809-6824. [CrossRef] [PubMed]

19. Li, S.S.; Wang, L.; Li, Y.D.; Zhang, L.H.; Wang, A.X.; Xiao, N.; Gao, Y.Q.; Li, N.; Song, W.Y.; Ge, L.; et al. Novel photocatalyst incorporating Ni-Co layered double hydroxides with P-doped CdS for enhancing photocatalytic activity towards hydrogen evolution. Appl. Catal. B 2019, 254, 145-155. [CrossRef]

20. Abellan, G.; Carrasco, J.A.; Coronado, E.; Romero, J.; Varela, M. Alkoxide intercalated CoFe-layered double hydroxides as precursors of colloidal nanosheet suspensions: Structural, magnetic and electrochemical properties. J. Mater. Chem. C 2014, 2, 3723. [CrossRef]

21. Ma, K.; Cheng, J.P.; Zhang, J.; Li, M.; Liu, F.; Zhang, X. Dependence of Co/Fe ratios in Co-Fe layered double hydroxides on the structure and capacitive properties. Electrochim. Acta 2016, 198, 231-240. [CrossRef]

22. Golovin, S.N.; Yapryntsev, M.N.; Ryltsova, I.G.; Veligzhanin, A.A.; Lebedeva, O.E. Novel cerium-containing layered double hydroxide. Chem. Pap. 2020, 74, 367-370. [CrossRef]

23. Damindarova, V.N.; Ryl'tsova, I.G.; Tarasenko, E.A.; Wang, X.; Lebedeva, O.E. Tin-Containing Layered Double Hydroxides. Pet. Chem. 2020, 60, 440-450. [CrossRef]

24. Ryltsova, I.G.; Nestroinaya, O.V.; Lebedeva, O.E.; Schroeter, F.; Roessner, F. Synthesis and characterization of layered double hydroxides containing Nickel in unstable oxidation state +3 in cationic sites. J. Solid State Chem. 2018, 265, 332-338. [CrossRef]

25. Gong, J.; Liu, J.; Wan, D.; Chen, X. Catalytic carbonization of polypropylene by the combined catalysis of activated carbon with $\mathrm{Ni}_{2} \mathrm{O}_{3}$ into carbon nanotubes and its mechanism. Appl. Catal. A 2012, 449, 112-120. [CrossRef]

26. Lin, T.J.; Meng, X.; Shi, L. Catalytic hydrocarboxylation of acetylene to acrylic acid using $\mathrm{Ni}_{2} \mathrm{O}_{3}$ and cupric bromide as combined catalysts. J. Mol. Catal. A Chem. 2015, 396, 77-83. [CrossRef]

27. Sayed, M.E.; Abukhadra, M.R.; Salam, M.A.; Yakout, S.M.; Aziz, I.M. Photocatalytic hydrogen generation from raw water using zeolite/polyaniline@ $\mathrm{Ni}_{2} \mathrm{O}_{3}$ nanocomposite as a novel photo-electrode. Energy 2019, 187, 115943. [CrossRef] 
28. Sarno, M.; Ponticorvo, E.; Scarpa, D. Novel Pt-Ni/NiO/ $\mathrm{Ni}_{2} \mathrm{O}_{3}$ based electrodes for electrocatalytic biodiesel production from waste palm oil. Mater. Today Proc. 2020, 20, 69-73. [CrossRef]

29. Tongamp, W.; Zhang, Q.; Saito, F. Preparation of meixnerite (Mg-Al-OH) type layered double hydroxide by a mechanochemical route. J. Mater. Sci. 2007, 42, 9210-9215. [CrossRef]

30. Su, Q.; Gu, L.; Yao, Y.; Zhao, J.; Ji, W.; Ding, W.; Au, C.-T. Layered double hydroxides derived Nix(MgyAlzOn) catalysts: Enhanced ammonia decomposition by hydrogen spillover effect. Appl. Catal. B 2017, 201, 451-460. [CrossRef]

31. Liang, H.; Lin, J.; Jia, H.; Chen, S.; Qi, J.; Cao, J.; Feng, J. Hierarchical NiCo-LDH/NiCoP@NiMn-LDH hybrid electrodes on carbon cloth for excellent supercapacitors. J. Mater. Chem. A 2018, 6, 15040-15046. [CrossRef]

32. Shivaramaiah, R.; Navrotsky, A. Energetics of Order-Disorder in Layered Magnesium Aluminum Double Hydroxides with Interlayer Carbonate. Inorg. Chem. 2015, 54, 3253-3259. [CrossRef] [PubMed]

33. Sławiński, W.A.; Sjåstad, A.O.; Fjellvåg, H. Stacking Faults and Polytypes for Layered Double Hydroxides: What Can We Learn from Simulated and Experimental X-ray Powder Diffraction Data? Inorg. Chem. 2016, 55, 12881-12889. [CrossRef] [PubMed] 